\title{
La estructura semántica de los nombres de color en la toponimia: la cromotoponimia de Gran Canaria
}

\section{REALIDAD Y LENGUA}

Las toponimias respectivas de cada zona geográfica pueden caracterizarse, entre otras muchas cosas, por el color; o sea, más que por el color del terreno, por los nombres de color que el hombre aplica a la geografía, que no es lo mismo, puesto que esa nominalización resulta siempre de una valoración subjetiva y no de una realidad objetiva.

Que los nombres de color resultan de una organización lingüistica y no de una clasificación objetiva de la realidad, lo demuestra el simple hecho de que en cada lengua hay tantos "colores" como nombres tenga para designarlos. "El espectro -explica Ullmann ejemplificando el mundo de los nombres de los colores en cada lengua - es una banda continua, y el número y naturaleza de las distinciones que superponemos sobre él son necesariamente arbitrarias y variables" ${ }^{1}$. El sistema griego, por ejemplo, era tan diferente del de las lenguas modernas y diferenciaba tan pocos colores que ha hecho pensar a alguien si los griegos clásicos fueron algo ciegos para los colores. En el latín no había ningún término para designar el color 'gris' o 'pardo', pero, sin embargo, tenían dos nombres para el blanco: albus para el 'blanco mate' y candidus para el 'blanco brillante'; y otros dos para el negro: correlativamente, ater y niger. En el lituano actual tampoco hay una palabra general para el color 'gris', teniendo que recurrir a términos específicos para el color gris del caballo, de la vaca, etc. Los navajos de Norteamérica distinguen dos clases de negro: el 'negro de las tinieblas' y el 'negro de los objetos', mientras que igualan en un solo nombre nuestros 'gris' y 'pardo', por una parte, y nuestros 'azul' y 'verde', por otra. Los indios bororos de las selvas brasileñas son capaces de distinguir nominalmente 17 colores de 'verde', mientras que en portugués sólo hay una palabra, verde ${ }^{2}$. Y, en fin, es también famoso el ejemplo

1 S. UllmanN, Semántica. Introducción a la ciencia del significado (Madrid: Aguilar, 1980) (2.. ed.), 278.

2 Cf. G. SAlVADOR, "Estructuralismo lingüístico e investigación dialectal", Revista Española de Lingüística, 7.2 (1977), 51-52. 
de que los esquimales disponen de hasta 13 nombres para diferenciar otros tantos tipos de nieve.

Lo que resulta diferente es la "visión" que los hombres pueden tener de un mismo fenómeno, a partir de la "discrecionalidad" lingüística. Es decir, a partir de un único continuum, como en este caso es el color, se pasa, a través de la lengua, a tantas unidades discontinuas como en cada lengua se lexicalicen en palabras diferentes. Esto resulta tan elemental y está tan en los principios de la semántica que sobra insistir en ello.

Fl color resulta de un proceso físico-psico-fisiológico de la visión que puede esquematizarse así ${ }^{3}$ :

$$
\begin{aligned}
\text { LUZ } & \rightarrow \text { OBJETOS } \rightarrow \text { OJO } \rightarrow \text { CEREBRO } \rightarrow \text { CORTEZA CEREBRAL } \\
\text { estímulo } & \rightarrow \begin{array}{l}
\text { impulsos } \\
\text { nerviosos }
\end{array} \rightarrow \text { sensación }
\end{aligned} \rightarrow \begin{aligned}
& \text { percepción } \\
& \text { consciente }
\end{aligned}
$$

La luz emitida por las fuentes luminosas -explica M. M. Espejo- llega directamente al ojo, o bien ilumina los objetos. La luz que estos objetos reflejan es la que incide sobre el órgano ocular. Por la acción de células sensisbles a la luz que se encuentran en una parte del ojo llamada retina, se generan impulsos nerviosos, los cuales son transmitidos por el nervio óptico al lóbulo occipital del cerebro, donde se produce la sensación, y de allí pasa a los centros superiores de la corteza cerebral donde tiene lugar la percepción consciente (Ibidem).

El color, o mejor, el nombre de los colores, no son entidades preexistentes a la lengua, sino producto de ella, de cada lengua funcional, entendida ésta como una lengua histórica (el español, el francés, el alemán, etc.) o como una "lengua dialectal" (el canario, el andaluz, el castellano, etc.). De ahí que sea distintivo en cada una de ellas -lengua historica o dialectal- no sólo el corpus léxico que se usa de ordinario en el habla, sino, sobre todo, la estructura semántica que se establece en ese conjunto léxico. A título de ejemplo, en el estudio citado de M.M. Espejo, que toma como fuente el DRAE, se registra un corpus de 389 nombres de color (aunque mejor sería decir palabras relacionadas con el color: adjetivos, sustantivos y verbos). Y no están todos, pues faltan términos tan comunes como gris, ceniciento, pardo, tiznado o zardo, por citar un conjunto del que trataremos nosotros en este estudio, seguramente por ser términos referidos al 'no color'. Pero lo más interesante, desde el punto de vista lingüistico. es la enorme diferencia con que en el español

"Tomamos el esquema y la explicación de M. M. Espejo MLRIEL, Los nombres de los colores en español (Granada: Universidad de Granada, Publicaciones de la Cátedra de Historia de la Lengua, 1990), 21. 
se ha lexicalizado cada color: se parte del hecho lógico — natural o físicode que cada color tiene un mismo espectro, una misma dimensión; y, sin embargo, la lengua ha procedido de manera muy diferente, "viendo" y estableciendo diferencias tan notorias como éstas: sólo 4 clases de 'anaranjado' (es decir, 4 términos definidos por el 'color anaranjado'), frente a 9 clases de 'violado', a 36 de 'azul', a 37 de 'verde', a 48 de 'amarillo', a 64 de 'blanco', a 84 de 'negro' y a 107 de 'rojo' 4 .

Pues la lengua opera sobre la realidad "color" organizando y combinando tres tipos de oposiciones semánticas:

a) oposiciones privativas: 'color' / 'no color', que opone, por ejemplo rojo / gris (que se pone de manifiesto en las expresiones comunes «en color" / "en blanco y negro"). Por ejemplo, en el lenguaje común la expresión "vestido de color" puede implicar cualquier color, pero excluye los vestidos de color blanco, negro y gris. Más explícito aún: el vestido de luto riguroso, el negro, antes de finalizar y pasar al "vestido de color", tiene un período intermedio que en Canarias, como en otros partes de España, se llama, muy elocuentemente, "alivio de luto", y que se dirige a los colores gris, marrón, morado o azul oscuro.

b) oposiciones equipolentes en las distintas tonalidades: 'rojo' / 'verde' / 'azul', etc. y que dan lugar a los nombres de todos los posibles colores; y

c) oposiciones graduales que, dentro de cada tonalidad, organizan la intensidad que se produce en cada color particular, y cuya gama puede ser interpretada en "grados" diferentes; por ejemplo, Espejo Muriel lo hace en cuatro grados: máxima, superior, normal y mínima ${ }^{5}$ y clasifica la tonalidad 'rojo' en los siguientes subconjuntos léxicos ${ }^{6}$ :

'rojo máximo': rojo

'rojo superior': cereza, granate, tinto, corinto, etc.

rojo normal': carmesi, coral, grana, encarnado, etc.

'rojo mínimo': bermejo, colorado, rojizo, etc.

\section{El COLOR DE LA GEOGRAFIA EN LA TOPONIMIA}

El color del terreno, bien sea por su propia composición geológica, bien por la presencia de la vegetación, bien por la acción del hombre

\footnotetext{
4 Repetimos que en la relación de M. M. Espejo faltan los términos del 'color gris'.

5 Op. cit., 20.

$6 \quad$ Ibid., 82-85.
} 
sobre el suelo, es uno de los elementos más a mano que el hombre tiene para denominar la geografía y para individualizar un punto del terreno dentro de su contorno. Tan llamativo o más que una elevación o una depresión resulta a la vista, por ejemplo, una peña blanca que contrasta con el risco negro al que pertenece. En algunos lugares, incluso, como se ha señalado para la toponimia argentina, el recurso de los colores se constituye en el rasgo más típico?. Tan importantes son los nombres de color en la toponimia de todas partes que forman un grupo individualizado que tiene su propio nombre: la cromotoponimia.

No puede esperarse, sin embargo, que en la toponimia se registren todos los nombres de color que se usan en el lenguaje común (como tampoco que en el habla popular se registren todos los nombres de color que están en el diccionario de la lengua), ni que haya una correspondencia perfecta entre el registro de éste con el de aquélla. La toponimia es un corpus léxico funcional, no cabe duda, puesto que se usa de continuo, al menos por el sector de la población a la que esa toponimia pertenece, pero también es verdad que la toponimia es un registro histórico, no siempre del todo sincrónico, por lo que se producen ciertos desajustes con el habla coloquial. Por ejemplo, no es extraño que en la toponimia pervivan nombres que han dejado de usarse en la lengua común, como courre con Pricto, que es adjetivo calificativo bastante común en la toponimia canaria. Y, al contrario, que falten totalmente en la toponimia o tengan una representación exigua, términos que son de uso común en la lengua actual, como Rojo, como después se verá.

Según la zona gengráfica de que se trate, hay cromotoponimias opacas. uniformes, y las hay brillantes, multicolores; y, en medio, una gama muy variada de escalas intermedias. Naturalmente, el que sean de una modalidad u otra depende en primer lugar de la naturaleza geológica, pero en segundo lugar, y no menos importante. de la lengua, pues un mismo colorbase puede tener dos, tres y hasta más nombres distintos que establecen matices y diferencias en la lengua. Como lo hace la toponimia de Canarias sobre la base del color 'rojo'. que, en el caso de Gran Canaria, se diversifica en, al menos, 12 unidades léxicas.

La cromotoponimia de las Islas Canarias es multicolor y brillante como pocas, aunque es verdad que ese cromatismo ni es uniforme ni igual en todas las Islas. Sería muy interesante comprobar con minuciosidad la cromotoponimia de cada Isla para compararlas entre sí y para enfrentarlas después con la realidad geográfica concreta a la que se refieren, con el supuesto de que la toponimia es más conserradora que la geografía,

\footnotetext{
Cf. I. Corominas. Tópica Hespénca (Madrid: Gredos, 19-2), vol. I, 126.
} 
mucho más en Canarias, en donde a la acción natural de los agentes de la naturaleza - las erupciones históricas y la erosión- hay que sobreponer la acción del hombre, que ha transformado profundamente su suelo.

Por lo que respecta a las Islas Canarias, tenemos datos que pueden darnos una aproximación al tema, pero no son homogéneos por cuanto representan "catas" muy distintas de la toponimia de cada Isla. De momento sólo podemos contar con los registros de los mapas militares, escalas 1:50.000 ó 1:25.000, excepto en la isla de La Palma donde contamos con un registro mucho más minucioso (aunque no publicado en su totalidad), hecho por C. Díaz Alayón ${ }^{8}$ para su tesis doctoral, y en la isla de Gran Canaria para la que, aquí sí, contamos con un nuevo y minuciosísimo registro que ha elevado a cerca de 13.000 los escuetos 2.400 topónimos que tenía el mapa militar de la Isla ${ }^{9}$. En otras varias islas, M. Alvar ha realizado encuestas toponímicas, con el propósito de confeccionar un "Corpus Toponymicum Canariense" general, pero de momento los resultados continúan inéditos y sólo sabemos de ellos lo que en dos "informes" ha redactado su autor respecto a la toponimia de Fuerteventura ${ }^{10}$ y de Lanzarote ${ }^{11}$. Así que aquí nos referiremos de continuo a la toponimia de Gran Canaria, de donde tomamos todos los datos, generalizando a la toponimia de todo el Archipiélago cuando los datos conocidos nos permitan hacerlo.

En otros corpus toponímicos peninsulares que pudieran servir de contraste con el de Gran Canaria, muy poca cosa podemos encontrar, bien porque en los respectivos estudios no se ha hecho una clasificación temática o semántica de los topónimos que permitan la comparación ${ }^{12}$, bien porque se estudia sólo la toponimia mayor, muy poco explicativa en lo que se refiere a la cromotoponimia ${ }^{13}$, etc. Dos excepciones conocemos y tenemos a nuestro alcance, que utilizaremos. La primera es la toponimia

8 C. DÍAz Alayón, Materiales toponimicos de La Palma (Cabildo Insular de La Palma, 1987).

" M. Trapero, J. Sú́rez Betancor, M. Lobo, V. Monteloncio y A. Romero, la toponimia de Gran Canaria: Recuperación. Clasificación y Estudio (Las Palmas de Gran Canaria: Cabildo Insular de Gran Canaria len prensal).

10 Ahora en M. Alvar, Estudios Canarios II (Las Palmas de Gran Canaria: Viceconsejería de Cultura y Deportes, 1993), 417-443.

11 Ibid., 445-476.

12 Por ejemplo en E. Tejero Roblero, Toponimia de Ávila (Ávila: Diputación Provincial. Institución Gran Duque de Alba, 1983).

13 Como en el caso de la toponimia de los Valles del Cea, Valderaduey y Sequillo, en las provincias de Palencia, León, Valladolid y Zamora. Cf. M. F. CARrera de LA RED, Toponimia de los Valles del Cea, Valderaduey y Sequillo (León: Diputación Provincial. Institución Fr. Bernardino de Sahagún, 1988). 
de los Oteros, en la provincia de León ${ }^{14}$, que estudia una comarca reducida en el tamaño, uniforme en el paisaje y bastante mate en el color: las tierras de transición entre la ribera leonesa y la tierra de campos castellana. En esa comarca la cromotoponimia se reduce a 8 términos: Mermejal (y Bermeja), Rubio, Rojo, Colorado, Almagre, Albera, Prieto $y$ Negro, y con muy pocos registros por cada uno de ellos ${ }^{15}$. El otro estudio toponímico, el de la Ribera de Cañedo, en la provincia de Salamanca ${ }^{16}$, es mucho más rico en cromotoponimia, resultando un cuadro de 22 nombres de color ciertamente variado y rico, que reproducimos ${ }^{17}$ :

\begin{tabular}{|l|l|l|l|l|l|l|}
\hline Negro & Blanco & Pardo & Rojo & Verde & Dorado & Moreno \\
& Blancadal & Ceniciento & Colorado & Verdejo & Doradillo & Bruno \\
Albo & & Rubiero & Verdero & Orio & \\
& & Alambrero & & & \\
& & & & & \\
& & & Rermejo & & & \\
& & Almagrero & & & \\
& & & & & & \\
\hline
\end{tabular}

\section{LOS NOMBRES DE COLOR EN LA TOPONIMIA DE GRAN CANARIA}

La lista de nombres de color que resulta en la toponimia de Gran Canaria, por orden alfabético, es de 41 términos; los siguientes: Almagre. Almagrés, Almagría, Amarillo, Ámbar, Azul. Azulejos, Barroso, Bermejal. Bermejo, Blanco, Blanquizal, Bragado. Calzado, Ceniciento, Cinta. Coloradas (Las). Colorados (Los). Coloradillo, Colorado, Encarnado, Lisos, Jovero, Mancho, Monteverde. Moreno. Negro. Oscuro, Pardilla. Plata, Platero. Prieto. Quemado. Rojo. Rosillo. Sardo. Tiznado, Verde, Verdejo, Verdeseca, l'erdugado y Zamora. Bien entendido que clasificamos sólo y estrictamente los nombres de color del terreno y no aquellos otros nombres que, por referirse a objetos que tienen un color determinado, pudieran tomarse por tales, como es el caso de nieve, que registra Coca Tamame ${ }^{18}$, y al que

it J. R MoRAla, Toponimia de la comarca de los Oteros (León) (León: Diputación Provincial, 1989).

15 Cf. especialmente las pp. 152-158.

in I. Coca TAMAME, Toponimia de la Ribera de Cañedo (Salamanca: Diputación Prorincial, 1993).

1. Ibid., 493 .

18 Op. cit. 4 ๆ9. 
podrían añadirse monte, por el color verde predominante, trigal, por el color verde o dorado que ofrece el campo sembrado de trigo, según la estación del año, etc.

Mas no todos los nombres tienen una presencia igual en la toponimia, cuantitativamente hablando; hay términos que aparecen calificando a un solo lugar, como Peñón Tiznado (Tejeda), otros a dos, como Morro Rosillo (Mogán) y Peñón Rosillo (Tejeda), y otros a muchísimos, como ocurre con Blanco, que es el nombre de color predominante, con mucho, de la toponimia de Gran Canaria. Por orden decreciente, los términos más usados en la cromotoponimia grancanaria son: Blanco y Blanquizal con más de 250 registros, Colorado y derivados con más de 80, Negro con unos 50, Bermejo y derivados con más de 40, Quemado con unos 30, Azul y Azulejos con unos 15, Amarillo con 7, etc.

Otro aspecto digno de destacarse en las generalidades de la cromotoponimia es la facilidad y frecuencia con que el nombre de un color, que empieza siendo morfológica y funcionalmente un adjetivo, se convierte en la toponimia en un sustantivo. Por ejemplo, es fácil explicar el paso de Lomas Coloradas a Las Coloradas (en la parte alta de la Isleta de Las Palmas de Gran Canaria), aunque no tanto el paso de Caidero Azul a Los Azulejos (en Mogán y San Nicolás de Tolentino), o de LLano Blanco a El Blanquizal (San Nicolás de Tolentino) o Los Blanquizales (Tejeda). Bien es verdad que el proceso de sustantivación de los cromotopónimos ni es general ni afecta a todos los términos, y en todo caso, los sustantivos tienen siempre una recurrencia mucho menor que sus correspondientes formas adjetivas. Este fenómeno de la sustantivación se produce en la toponimia con mucha menos frecuencia que en la lengua común. Espejo Muriel ${ }^{19}$, sobre la base del DRAE, calcula un 53 por 100 de adjetivos frente a un 22 por 100 de sustantivos. En la toponimia de Gran Canaria, por su parte, aun sin haber hecho un recuento exhaustivo al respecto, estimamos que los adjetivos deben representar el 85 por 100 del total, frente a los sustantivos que representarán un 15 por 100 .

\section{ESTRUCTURAS SEMÁNTICAS EN LA CROMOTOPONIMIA}

El mayor interés que puede tener el estudio de un conjunto léxico, sea éste del dominio general del lenguaje o de una parcela concreta del mismo, caso de la toponimia, radica en nuestra opinión en las relaciones semánticas que se establecen en él. El léxico funcional de una lengua no

\footnotetext{
19 Op. cit., especialmente en los gráficos y relaciones finales.
} 
es una larga lista de nombres sin más orden que el alfabético; por el contrario, el léxico funcional se organiza según estructuras semánticas que parcelan el léxico general en microcampos funcionales bien delimitados. Incluso dentro del léxico de la toponimia, más allá de los nombres propios específicos de un único lugar, como Madrid, Toledo, Tenerife, Agaete o Guiniguada, los apelativos se organizan según un criterio semántico, y así podemos hablar de orónimos, de hidrotopónimos, de antropónimos, de hagiotopónimos, etc. Y también, por supuesto, de cromotopónimos. El interés de la cromotoponimia no se agota, como ha solido en la mayoría de los estudios existentes al respecto, en la etimología, con ser ésta cuestión de principal atención. Las estructuras semánticas que se establecen en los registros toponímicos de cada lugar es un campo de estudio que, por ignorado, se presenta como una de las perspectivas más interesantes, fructíferas y novedosas de los estudios de toponomástica. Y en ella queremos centrar el presente estudio.

Nos resulta especialmente acertada y útil la ordenación que de los nombres de color en el español normativo hace Espejo Muriel en su trabajo (itado, sobre una escala cromática que se organiza así:

\begin{tabular}{|l|l|l|l|l|l|l|l|}
\cline { 3 - 6 } & \multicolumn{1}{|c|}{ blanco } & \\
\hline -olado & rojo & anaranjado & amarillo & verde & azul & violado & ro- \\
\hline
\end{tabular}

De esta propuesta se desprende que:

a) El continuum 'color' no se organiza en una escala lineal, que se extienda longitudinal e infinitamente, sino que, por el contrario, es una organización circular y cerrada, en donde cada tonalidad de color ocupa un lugar fijo y determinado y en la que la escala se inicia en el mismo punto en que termina. De ahí que las casillas de los extremos de la escala no estén cerradas, sino abiertas para unirse en un movimiento circular.

b) Los nombres de color, o mejor, los sememas que dan lugar a los nombres de color, están ordenados según las oposiciones equipolentes: 'rojo' 'anaranjado', 'amarillo' / 'verde' / 'azul' / 'violado'.

c) La oposición equipolente anterior se torna en oposición privativa en el caso de los sememas blanco' / 'negro', que entre sí resultan excluyentes.

d) Dentro de cada recuadro del gráfico, cada semema se lexicaliza en una serie de términos opuestos entre sí por el rasgo semántico intensidad de color', con lo que entre ellos se constituyen oposiciones graduales. Estas oposiciones graduales se producen en dos sentidos: en sentido rertical, dentro de cada tonalidad, de más intensidad a menos, por ejem- 
plo, en la tonalidad 'rojo': rojo / encarnado / colorado / bermejo, etc., y en sentido horizontal, mezclando las tonalidades de las casillas vecinas, por dispersión del color, resultando, por ejemplo, de la dispersión del 'amarillo' al 'rojo': herrumbroso y rubicundo; del 'amarillo' al 'naranja': azafrán; del 'amarillo' al 'verde': cetrino; del 'amarillo' al 'blanco': escarolado; etc.

Ahora bien, ni todos los cromotopónimos que aparecen en la toponimia de Gran Canaria están registrados en el DRAE como nombres de color -y por tanto tampoco en los conjuntos léxicos estudiados por Espejo Muriel, caso, por ejemplo, de los canarismos Jovero, Quemado y Zamora-, ni los grupos representados en el gráfico anterior agotan las posibilidades de clasificación del archisemema 'nombres de color'. Tres nuevos grupos requerimos nosotros para ubicar en ellos una serie de cromotopónimos grancanarios que no hallan ahora acomodación: en primer lugar, el grupo de los que manifiestan el semema 'no color' (cuyo archilexema en espanol parece ser gris) y que justamente se excluye de la relación léxica de Espejo Muriel: nombres como Ceniciento, Tiznado, Pardo o Verdugado, que aparecen en la toponimia de Gran Canaria no encontrarían acomodo en su clasificación; en segundo lugar, el grupo de los nombres que no designan un color determinado, sino sólo el de servir de contraste con el color predominante del resto del territorio y que expresamos con el semema 'color de contraste', representado en Gran Canaria por los topónimos Calzada, Bragado, Lisos y Mancho; y en tercer lugar, el de los nombres que manifiestan no un solo color, sino varios colores combinados, como es el caso de Azulejos, de una gran frecuencia en la cromotoponimia canaria.

Debe destacarse también en la cromotoponimia de Gran Canaria la ausencia total de términos de las tonalidades 'anaranjado' y 'violado' (de la escala propuesta por Espejo Muriel 1990: 26). Y, además, otros términos que resultan muy comunes en las toponimias peninsulares, como Alba y derivados (Albos, Alberas, etc.), Rubio y derivados (Rubial, Rubiero, Rodal, Roal, etc.) (en la toponimia de Gran Canaria aparece Rubio pero sólo como antropónimo), Dorado y derivados (Doradillo, Orio, etc.), Bruno, etc. y es también muy significativa la escasísima presencia de Rojo, que comentaremos en su lugar.

Procederemos, pues, al estudio de cada término dentro del grupo clasificatorio al que pertenece y ordenándolo según el rasgo de intensidad de color, de más a menos.

\section{LOS NOMBRES DE 'COLOR BLANCO'}

El blanco es, sin duda ninguna, el color predominante de la toponimia canaria - aunque no sea el más lexicalizado-, y además en una propor- 
ción desmesurada respecto a los demás colores, lo que explica que en la Isla de Gran Canaria aparezcan más de 250 lugares con este nombre o alguno de sus derivados.

Desde el punto de vista semántico, es también el menos marcado; es, como dice el DRAE, "el color de la luz solar, no descompuesta en los varios colores del espectro". Resulta curiosa, por otra parte, la práctica lexicográfica del DRAE (y de los demás diccionarios españoles, que en esto, como se sabe, siguen el modelo del diccionario académico) de definir el color a través de comparaciones: un color "es" el que tiene un elemento o una cosa muy común, caracterizada por ese color. Así, 'blanco' es el color de la nieve y de la leche; 'negro' el del carbón; 'rojo' el de la sangre; 'verde' el de la hierba fresca, la esmeralda y el cardenillo; etc.

En cuanto a la estructura semántica del paradigma, se organiza según la intensidad, desde el grado normal que representa blanco, que es la indiferencia significativa de esa cualidad, hasta los grados inferiores de blanquizal y plata. Gráficamente:

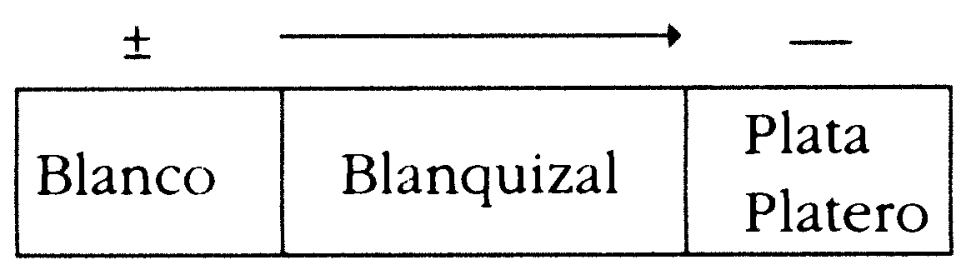

\section{BLANCO}

Mayoritariamente es la forma adjetiva Blanco, - $a$ la que aparece para calificar a todo tipo de accidente natural del terreno (una montaña, un risco, un lomo, una piedra, una cueva, etc.) o para cualquier otro elemento elaborado (una casa, una cruz, un corral, etc.), representados por topónimos como Cuevas Blancas (Las Palmas de Gran Canaria, San Bartolomé de Tirajana, etc.), Degollada Blanca (Tejeda) o Casa Blanca (en todas partes). Es de señalar que este último topónimo aparece algunas veces escrito junto, sintiéndose en ese caso el adjetivo totalmente lexicalizado al nombre: Casablanca es ya un topónimo meramente designativo, que ha perdido la capacidad significativa del adjetivo calificativo.

Un caso particular de sustantivación desde el adjetivo Blanco, lo presentan topónimos como Lo Blanco (escrito separadamente, de manera análoga a Lo Seco), como Barranquera de Lo Blanco (Las Palmas de Gran Canaria). Pero esta forma puede interpretarse también como un caso de apócope de Lomo, como en Loblanco y Barranquera de Loblanco (Las Palmas de Gran Canaria), no infrecuente en la toponimia de Gran Canaria. 


\section{BLANQUIZAL}

Como derivado morfológico de blanquizo, se registra también en Gran Canaria con relativa frecuencia el sustantivo Blanquizal, con la referencia específica de 'terreno gredoso', tal cual señala el DRAE, en topónimos como Los Blanquizales (Agaete, Moya, Tejeda, etc.), Finca del Blanquizal (Gáldar) o Cañadón del Blanquizal (San Nicolás de Tolentino).

\section{PLATA. PLATERO}

Hay una serie de topónimos en Gran Canaria cuyo término específico Plata nada tiene que ver con el "metal blanco, brillante, sonoro, dúctil y moldeable, más pesado que el cobre y menos que el plomo", que define el DRAE, sino con el sentido del adjetivo que también recoge el DRAE-92 en su acepción 9: 'plateado, de color semejante al de la plata', y específicamente la $3 .^{a}$ acepción del DUE de M. Moliner: 'color blanco'. Ni en los suelos de Canarias ha habido nunca plata ni en la historia de las Islas ha habido comercio que explique y justifique tantos topónimos así nombrados y en lugares tan impropios para el comercio, como Hoya de la Plata (Las Palmas de Gran Canaria), Barranco de la Plata (San Bartolomé de Tirajana), Llano de la Plata (Guía), Paso de la Plata (San Bartolomé de Tirajana), o simplemente La Plata (San Bartolomé de Tirajana y Valsequillo). Por el contrario, el color blanquecino de los suelos de esos lugares los iguala y hace semánticamente motivado el nombre que tienen.

De la misma manera debe interpretarse el Lomo Platero que hay en San Nicolás de Tolentino.

\section{LOS NOMBRES DE 'COLOR NEGRO'}

Desde el punto de vista conceptual, "lo negro" no representa un color determinado, sino, justamente, la falta de todo color, como señala el DRAE; pues teniendo el color la naturaleza de la luz solar, lo negro representa la ausencia de la luz, y en este sentido se basa la oposición dia / noche, caracterizada por la 'presencia' / 'ausencia de la luz solar'. Sin embargo, en la lengua, negro sí se refiere a un color determinado: "color totalmente oscuro, como el carbón", dice el DRAE, en oposición al semema 'no color', propio de gris.

En realidad, el término negro, ya sea en la toponimia o en la lengua general, tanto puede expresar la intensidad máxima del negro, "de color 
totalmente obscuro, como el carbón" — dice el DRAE-, como la más genérica y neutra, "obscuro u obscurecido y deslucido, o que ha perdido o mudado el color que le corresponde", que también dice el DRAE en su $4{ }^{2}$ acepción, actuando en este caso como verdadero archilexema del conjunto léxico correspondiente.

Pues el color negro u oscuro está lexicalizado en la toponimia de Gran Canaria por los términos Negro, Prieto, Quemado, Moreno, Oscuro y Tiznado, por este orden de intensidad del color, que podemos representar gráficamente:

\begin{tabular}{|l|l|l|l|l|l|}
\hline Negro & Prieto & Quemado & Moreno & Oscuro & Tiznado \\
\hline
\end{tabular}

\section{NEGRO}

El término Negro, con más de 50 recurrencias en la toponimia de Gran Canaria funciona siempre como adjetivo para calificar a todo tipo de accidentes naturales del suelo, como una montaña, un risco, un caidero, un morro, un andén, etc. Un topónimo hay en Gran Canaria que reúne casi todas las combinaciones léxicas posibles hasta hacerlo acumulativo al máximo: Morro del Llano de Montaña Negra (San Bartolomé de Tirajana). Sólo en dos ocasiones encontramos el adjetivo calificando a una especie vegetal, como La Rosa Negra (Tejeda) o Rosal Negro (Agaete).

A diferencia de Blanco, el término Negro 'color del terreno' no se sustantiva en la toponimia de Canarias, y si lo hace es con otra referencia significativa, para indicar un lugar caracterizado por 'persona de raza negra', como ocurre en La Negra (San Bartolomé de Tirajana), equivalente a Morro de la Negra (Tejeda), frente a Morro Negra (San Mateo), o Barranco del Negro (en los términos de Telde y de San Bartolomé de Tirajana), frente a Barranquillo Negro (Arucas), siendo que los primeros recuerdan la presencia de los negros africanos en las Islas en la época de la esclavitud para el cultivo de la caña de azúcar.

\section{PRIETO}

Como un verdadero arcaísmo hay que considerar la presencia de Prieto en la toponimia de Canarias, ya que el término ha desaparecido de la lengua común con el valor de 'color muy oscuro'. Etimológicamente deriva del verbo apretar, que tomó en castellano antiguo y portugués el valor de 'negro, moreno' desde el significado primitivo de 'denso, apretado' (DCECH: apretar). 
En la toponimia de Gran Canaria lo encontramos abundantemente calificando a accidentes naturales del suelo: LLanos Prietos (Agüimes), Barranco Prieto (Valleseco), Roque Prieto (Guía), etc. Su presencia tan abundante en la toponimia puede deberse al influjo de los portugueses en las Islas, pues en portugués es término común incluso en la actualidad.

\section{QUEMADO}

Son muchísimos los lugares que en Canarias se llaman Los Quemados o Los Quemadillos, aparte los otros topónimos en los que este término aparece como calificativo, como en Lomo Quemado, Andén Quemado. Montaña Quemada, etc. Podría ofrecer dudas el que ciertos topónimos, como Casa Quemada o Cruz Quemada, incluso Lomo de los Quemados, se refirieran a lugares o edificios quemados por el fuego, pero en la mayor parte de los casos la toponimia nos remite a otro tipo de realidad: a lugares cubiertos por ríos eruptivos de lava, a lugares de volcán, siempre de color negro.

De donde, por deslizamiento semántico, el color se convierte en rasgo definidor pertinente del topónimo.

\section{MORENO}

Aparte de otros valores que pueden tener los términos Moreno y Morena cuando aparecen en la toponimia como sustantivos, a saber:

a) 'persona de raza negra', equivalente a Negro, como en Barranco del Moreno (Telde), determinado por la preposición de + el artículo, bien en masculino o en femenino;

b) 'antropónimo', como en Hoya de Moreno (Guía), con la preposición, pero sin el artículo, y generalmente en masculino;

c) 'pez teleóstero marino', siempre en topónimos de costa, como Punta de las Morenas, con preposición y artículo, siempre en plural y como femenino (pues el macho de la morena se llama en Canarias "murión");

d) 'montecillo de piedras y tierras arrastradas por las aguas correntías' ${ }^{20}$, que se forman en los barrancos o en los cauces, como en Barranco de las Morenas (Teror), siempre en femenino y en plural.

En la toponimia, con el valor de 'color oscuro, que tira a negro', funciona como adjetivo, en este caso unido al sustantivo sin elemento de relación alguno, para calificar a ciertos accidentes del terreno, como Cuevas Morenas o Lomo Moreno (los dos en el término de Teror). Pero el calificativo Moreno es raro en la toponimia de Gran Canaria, prefiriéndose, con mucho, los términos Negro y Prieto.

20 A Galmés, Toponimia de Alicante rla oronimia) (Universidad de Alicante: Col.lecció Xarc Al-Andalus, 1990), 1T. 


\section{OSCURO}

En la toponimia de Canarias, el término Oscuro tiene dos acepciones diferentes: el primero se refiere a la abundancia de vegetación que hay en ese punto, lo que hace que contraste en color con el contorno, como en Hoya Oscura (Moya y Santa Brígida), siendo, sí, de color oscuro, pero más por el verde que por el negro, equivalente en este sentido a Mancha o Manchado, tan frecuentes en la toponimia canaria. La otra acepción de Oscuro, mucho más frecuente, se corresponde con el significado más general del español 'que tira a negro', aplicado en la toponimia de Gran Canaria a aquellos accidentes del terreno que, por su profundidad y estrechura, apenas si tienen luz, como Barranco o Barranquillo Oscuro (Agaete, Artenara, Moya y Gáldar), Caidero Oscuro (Mogán y San Nicolás de Tolentino) o Cueva Oscura (Agaete).

\section{TIZNADO}

Con el mismo valor que tiene en el lenguaje común, Tiznado 'marcado de tizne', de un color oscuro, negruzco, se registra el término como calificativo de un peñón, formando el topónimo Peñón Tiznado (Tejeda); aunque es posible que el valor semántico aquí sea simplemente 'de un color diferente al resto del contorno' y que siendo así debiera clasificarse con los nombres del grupo 'color de contraste'.

\section{LOS NOMBRES DE 'COLOR ROJO'}

Comparativamente, que es el modo que habitualmente toman los diccionarios para definir los colores, se dice que es 'rojo' lo que es semejante al color de la sangre.

Pues el color 'rojo' es, sin duda, el más llamativo de la gama cromática (el primero del espectro solar), y quizá por ello el que más lexicalizados tiene sus diferentes matices cromáticos en el lenguaje común ${ }^{21}$ : 107 términos, frente a 84 del negro, a 64 del blanco, a 37 del verde, etc.). Y esa doble característica, lo llamativo que resulta el color y la riqueza léxica en la que se manifiesta, se refleja de una manera muy notable en la toponimia de Canarias, que halla en los suelos volcánicos de las Islas una espléndida realidad en la que poner a prueba la eficacia de todo el conjunto léxico.

\footnotetext{
2 Cf. Espejo Muriel, op. cit., especialmente 37-87.
} 
Por lo que respecta a la toponimia de Gran Canaria se documentan los siguientes términos base, en orden decreciente de mayor a menor frecuencia: Colorado, Bermejo, Almagre, Zamora, Sardo, Rosillo, Rojo, Encarnado y Barroso. Y en orden a la intensidad del color, la escala gradual (siguiendo a M. M. Espejo), de más a menos, sería: a) en la escala máxima: Rojo; b) en la escala superior, ninguno; c) en la escala normal: Encarnado, Colorado y Almagre (y sus derivados); y d) en la escala mínima: Bermejo, Zamora, Sardo, Rosillo y Barroso. Gráficamente:

\begin{tabular}{|c|c|c|c|}
\hline \multicolumn{2}{c}{+} & \multicolumn{3}{c}{} & \multicolumn{1}{c|}{} \\
\hline Rojo & & Encarnado & Bermejo \\
& & Colorado & Zamora \\
& & Almagre & Sardo \\
& & & Rosillo \\
& & & Barroso \\
\hline
\end{tabular}

ROJO

Lo más llamativo resulta ser que Rojo, que es el término más genérico en el español moderno, el archilexema del conjunto léxico y por ello el de mayor frecuencia de uso, se aparta de estas características en el lenguaje toponímico. En la toponimia no es, ni mucho menos, el término más usado. Y hasta podría decirse que es un término "anómalo" en los registros toponímicos más antiguos de Canarias. En Gran Canaria se registran sólo dos casos: Vuelta Roja (Agaete) y Rocas Rojas (San Bartolomé de Tirajana), y podemos asegurar que uno de ellos, el segundo, es moderno y no patrimonial en el léxico toponímico, un nombre impuesto muy recientemente a una urbanización turística del sur de la Isla, caracterizado el lugar, eso sí, por la presencia de rocas rojas. Esta ausencia de Rojo en la toponimia de Canarias no es una "anomalía" del léxico de la toponimia, sino que este registro es simple reflejo de la lengua funcional de las Islas, donde la palabra rojo puede decirse que ha sido extraña al léxico tradicional, como ya pusieron de relieve Almeida y Díaz Alayón. "Un caso especialmente interesante a este respecto -dicen los autores citados- es el comportamiento del par rojo-encarnado. En la lengua de Viera y Clavijo (Diccionario de Historia Natural) ambos vocablos alternan en el uso, pero en la actualidad la primera de estas unidades resulta muy extraña de encontrar funcionando activamente en el habla de sujetos, sobre todo en zonas rurales, que superan los cuarenta años y que utilizan encarnado o colorado. En este caso, el elemento rojo no funciona en el habla común con el valor cromático original, sino como referencia a una circunstancia 
reciente de la historia natural" ${ }^{22}$. La toponimia, que es el registro léxico más antiguo y patrimonial con que se puede contar para constatar los usos dialectales de un lugar, viene a corroborar esa realidad.

No son extraños en Canarias, sin embargo, topónimos como Cañada de Rojas o Palma de Rojas (los dos en Mogán), pero que son referencias a antropónimos, como bien declara el régimen preposicional de los dos casos.

\section{ENCARNADO}

El 'color rojo' que significa este término está referido por su propio significante: 'del color de la carne'. Y si es muy común en el habla popular de las Islas, por ejemplo para designar un tipo de viejas 'pez' (aunque se prefiere la expresión "vieja colorada"), a una clase de calabazas, al caballo alazán, al color del cielo del arrebol, a un tipo de manzanas, etc. ${ }^{23}$, en la toponimia es rarísimo, por no decir desconocido, pues la única vez que (o) registramos en Gran Canaria lo es para denominar a una Casa Encarnada (del término municipal de Moya), que da nombre a un lugar en el que lo más destacado en el momento de ponerle el topónimo debió ser la existencia de una casa pintada de rojo.

\section{COLORADO}

Etimológicamente deriva de color, por ser el color por excelencia, el más llamativo al sentido de la vista, pero el significado 'rojo', o mejor, 'rojizo' (que es de una intensidad menor), no lo toma hasta el siglo XV (DCECH), y desde esa época comienza a desplazar en el uso al término bermejo y a otras formas más antiguas hasta convertirse en uno de los términos más empleados para el semema rojo".

El término más común en el español de Canarias para el significado "color rojo" es, y con mucho sobre todos los demás, Colorado. "Colorado" se llama especialmente al gallo de pelea; "colorada" se llama a una variedad muy estimada del pez vieja; "higuera colorada" a una clase de higueras; "ierra colorada" a la tierra de composición arcillosa; "vaca o cabra coloradas" a las de pelo canelo; "cielo colorado" al arrebol; etc. ${ }^{24}$ También en

$\therefore$ M. Almeida y C. Diaz Alayon, El español de Canarias (Santa Cruz de Tenerife, 1988), 200 .

iz Cf. TleC $=$ C. Corraless, M. A. Álvarez Martinez y D. Corbellá, Tesoro lexicográfico del español de Canarias (TLEC) (Madrid: Real Academia Española y Consejería de Educación. Cultura y Deportes del Gobierno de Canarias, 1992).

it Cf. todos ellos, y más, en el TLEC. cit. 
la toponimia el término Colorado es el más frecuente de toda la serie léxica: más de 60 riscos, montanas, cuestas, cuevas, llanos, andenes, caideros, lomos, morros, roques, andenes, barrancos y tierras de Gran Canaria son apellidados Colorados. Tan común es el calificativo que ha llegado a sustantivarse, y así encontramos con mucha frecuencia topónimos como Las Coloradas (Las Palmas de Gran Canaria, Arucas, San Nicolás de Tolentino, etc.) por 'lomas coloradas', 'tierras coloradas' o cualquier otro accidente cuyo nombre genérico sea femenino; y Los Colorados (Artenara, San Bartolomé de Tirajana, Teror, etc.) aplicados a accidentes cuyo nombre genérico sea masculino.

\section{COLORADILLO}

Un caso particular de lexicalización en la toponimia sobre el término colorado, es el caso de El Coloradillo (San Nicolás de Tolentino) (también se registra en plural en Mogán y San Nicolás de Tolentino), que no es un diminutivo gramatical para referir la aminoración del color, sino un diminutivo lexicalizado para indicar la pequeñez del accidente calificado.

\section{ALMAGRA. ALMAGRE. ALMAGRÉS. ALMAGRÍA}

La tierra almagre - dice nuestro Viera y Clavijo- "es una especie de ocre rubicundo, cargado de partículas de hierro, que en quemándolo se pone más oscuro y del cual usan los pintores para dar el color de caoba a las maderas. Es muy común en nuestras islas, y sus vetas son más o menos rojas, más o menos ricas, más o menos compactas. [...] No sólo se aprovechan los pintores de esta sustancia, sino también se valen de ella nuestras olleras y loceras para harnizar sus búcaros, tallas y cantarillas, dándoles un bruñido y un colorido agradable ${ }^{25}$.

En efecto, el color rojizo que tiene es el rasgo más sobresaliente de este tipo de tierra, improductiva para el cultivo pero muy útil en la confección de la cerámica popular y, sobre todo, muy vistosa para el paisaje. De donde han quedado fijados en la toponimia de todas las Islas nombres como Almagría 'lugar en que hay almagre' (Agüimes y San Mateo), Almagrera 'lugar donde se extrae el almagre' (Valsequillo, Valleseco y San Mateo), Almagrés (Montaña Almagrés, en Mogán) y hasta Almagra (Lomo de la Almagra, en Gáldar). Es un arabismo común en el español general.

25 J. Viera y Clavijo, Diccionario de Historia Natural. Ed., estudio y notas de M. Alvar (Las Palmas de Gran Canaria: Cabildo Insular, 1982), s. v. 
BERMEJO

Procede del lat. VERMICULUS 'gusanillo, cochinilla', por el color rojo oscuro intenso que producía este insecto (tan cultivado en Canarias en épocas pasadas como tinte natural muy estimado), pero ya en el latín vulgar toma el sentido de 'encarnado' con el que pasa al romance, aunque aplicado al terreno sólo se documenta a partir del siglo XV (DCECH).

Sobre el matiz de 'color rojizo', el término bermejo no es extraño al léxico común del español de Canarias, sino que, al contrario, se aplica a las más variadas realidades, como a las cabras y a las vacas de color canelo, a la tierra arcillosa, y bermejuela se llama a una clase de uva (cf. TLEC). Pero sin duda, el término Bermejo ha encontrado en la toponimia su campo de aplicación principal. Y así, lo hallamos repetidísimo calificando tanto a una degollada, como a una cueva, a una fuente, a una hoya, a una huerta o a una montaña.

No es infrecuente oírlo en el lenguaje rural canario con la variante Bremeja, por metátesis, o como Mermeja, por asimilación de consonantes, que es la forma de los viejos textos castellanos, conservada en la literatura oral de las Islas, como en el romance de "Río Verde, Río Verde" de La Gomera, la única versión moderna conocida de este romance fronterizo:

Sobre ti, Peña Mermeja, murió gran caballería ${ }^{26}$

\section{BERMEJAL}

Tan frecuente es el adjetivo Bermejo en la toponimia de las Islas que se ha sustantivado como El Bermejal (Moya, Gáldar, Valleseco, etc.; y también en plural, Los Bermejales, en Moya), en este caso para referirse sólo a un tipo de terreno arcilloso, caracterizado por su color rojizo.

\section{ZAMORA}

Constatamos la presencia de la palabra Samora o Zamora en la toponimia de Gran Canaria en nueve registros diferentes en los términos de San Nicolás de Tolentino, Valleseco, Agüimes, Telde, San Bartolomé de Tirajana y Santa Lucía de Tirajana, es decir, prácticamente por toda la isla. Pero no podemos asegurar si su grafía es con $s$ o con $z$, pues desconocemos su etimología, bien es verdad que en el habla se oye siempre / samora/. por ser el seseo la norma dialectal canaria. M. Alvar transcribe

26 Cf. M. TRAPERO: Romancero de la isla de La Gomera (Madrid: Cabildo Insular de l.a Gomera, 1987), núms. 21-24. 
tierra samora, con el valor de 'arcilla, tierra rojiza', y también 'greda, tierra blancuzca que se queda pegada a los dedos', que recogió en dos puntos de Gran Canaria ${ }^{27}$. Sin embargo, en la toponimia que se da por escrito, aparece con $z$, y hay un pago bien conocido de Valleseco que ha entrado en los mapas, en los carteles de carretera y en la memoria visual de los habitantes de la isla escrito siempre con $z$.

En efecto, en la toponimia, aparte de éste, hay otras Zamoras que no sabemos si interpretar como gentilicio o traslación del nombre de la provincia española, o como lugar abundante en 'tierra zamora'. Pero hay otros que constatamos inequívocamente como pertenecientes a este segundo sentido, tales como dos Montaña Zamora (San Bartolomé de Tirajana y Telde), un Barranco y un Barranquillo de Zamora (Valleseco) y una Tierra Zamora (Santa Lucía de Tirajana).

Dos propiedades tiene esta "tierra zamora": su color abermellado o morado intenso y el ser impermeable cuando se humedece, razón esta por la que esta tierra se usaba mucho como "tierra de torta" para los techos de las casas rurales, pajeros y chozas. Pero la propiedad de su color es la que determina su nombre.

Ni el DRAE, ni Corominas, ni García de Diego, ni ningún otro diccionario al uso dan cuenta de la posible etimología de esta palabra. Sólo L. Cortés aventura una explicación etimológica en un artículo suyo que titula precisamente "Un problema de la toponimia española: El nombre de Zamora" ${ }^{28}$. Entre otros étimos posibles, propone Cortés la palabra beréber $A Z E M I / R$, con el significado 'acebuche, olivo silvestre', que ha dejado muchos topónimos por el norte de Africa con nombres como Zemmora, Zamoura o Zamora; y el celtismo SEMURE que explicaría las formas primitivas con que aparece mencionada la capital del Duero: Senure, Senimure, Seniure y Sumere evolucionadas hasta la actual Zamora por etimología popular. Mas ninguna de estas etimologías explica el significado 'color rojo' que inequívocamente tiene en la toponimia y en el habla grancanaria.

\section{SARDO}

El DRAE dice de sardo, en su $3 .^{a}$ acep., que se aplica al "ganado vacuno cuya capa tiene mezcla de negro, blanco y coloradom. Sin embargo, en Canarias se usó para llamar a las personas de pelo rojo. Así lo recogen los

27 Cf. M. Alvar, Atlas lingüístico y etnográfico de las Islas Canarias (ALEICan) (Las Palmas de Gran Canaria: Cabildo Insular, 1975-1978), vol. II, 773, GC 30 y GC 2, respectivamente.

28 Publ. en Zephyrus, III (1952), 65-74. 
hermanos Millares: "Aquí, en Canarias — dicen—, no abundan los individuos de pelo rojo. Predominan los morenos, o sea el tipo andaluz, y no escasean los rubiancos, vestigios tal vez de la raza indígena. Pues bien, a las personas que tienen 'poil de carotte', se les llamó sardos sin que me conste el origen de la palabra ni si es o no de uso en otras regiones españolas" 29.

En la toponimia de Gran Canaria han quedado dos topónimos El Sardo (Las Palmas de Gran Canaria) y una Hoya del Sardo (Ingenio) que se refieren al color del terreno de esos lugares y, por tanto, funcionan como cromotopónimos.

O sea, que sardo, de ser primeramente un nombre de color de los animales, pasó luego a calificar a las personas, como apodo, y llegó por último a la geografía, como topónimo.

ROSSILLO

El color más apagado del rojo, tirando a gris, se lexicaliza en el habla popular de las Islas en rosillo, especialmente para designar a las cabras. "I.o que cualquier hablante designa como 'castaño claro' -dice $M$. Almeida, refiriéndose al habla de Gran Canaria- en el habla de los cabreros se transforma en rosillo o bayo, según el color tienda más al oscuro o al claro" "

Fn la toponimia de Gran Canaria se registra este término como adjetivo calificativo de un Morro (en Mogán) y de un Peñón (en Tejeda).

\section{BARROSO}

El topónimo Lomo Barroso (San Nicolás de Tolentino) no designa a un "terreno o sitio que tiene barro o en que se forma barro fácilmente", tal como define el DRAE a barroso en su $1 .^{a}$ acep., sino que se refiere al color que tiene alli el terreno, justamente "del color del barro, que tira a rojo", como también lo define el DRAE en su $2 .^{a}$ acep. Con lo que el topónimo en culestión es un cromotopónimo y no un orotopónimo.

\section{LOS NOMBRES DE 'COLOR AMARILLO'}

La tonalidad 'amarillo', definida en todos los diccionarios como 'del color semejante al del oro, al limón, a la flor de la retama, etc., y que TLEC.

En Cómo bablan los canarios (Las Palmas de Gran Canaria, 1932); cit. por el

") M. Almeida: El habla mural de Gran Canaria (Universidad de Gran Canaria: Secretariado de Publicaciones, 1989), 184. 
es el tercer color del espectro solar, no parece ser uno de los más comunes de nuestros suelos, está lexicalizado en la toponimia de Canarias por su propio lexema Amarillo, por Ámbar y por Jovero, por este orden de intensidad de color y frecuencia, en todos los casos con escasos registros. Gráficamente:

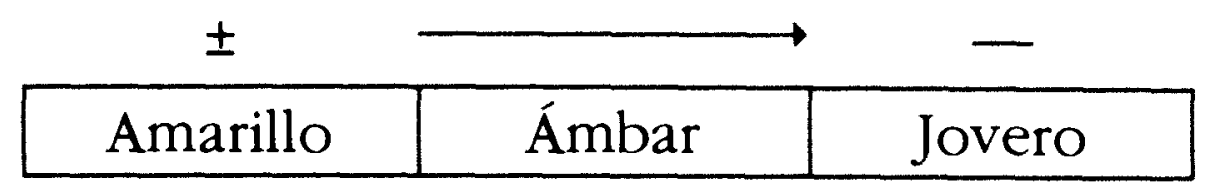

\section{AMARILLO}

El primero, amarillo, aparece como adjetivo calificativo de varias Lajas Amarillas (en los términos de Agaete, Artenara y San Nicolás de Tolentino) y de una Veta Amarilla (Tejeda), sin otro comentario especial.

\section{ÁMBAR}

El término ámbar, de designar primeramente 'resina fósil producto de animales marinos', de color amarillo más o menos intenso, ha pasado a significar también el mismo 'color amarillo'. Y con estas dos acepciones se registra el término en la toponimia de Gran Canaria.

Precisamente Viera y Clavijo, tratando sobre cuál sea el origen y la naturaleza del ámbar (atribuyéndolo unos a los excrementos de ciertas aves; otros a gomas de algunos árboles; otros a betún mineral; otros a panales de abejas....") dice que los canarios creen que sea "excremento de las ballenas", por lo que cuando se encuentran en las playas "una pella de ámbar" no dicen sino "una ballena de ámbar" ${ }^{31}$. De ahí que cuando el topónimo sea de costa, como Playa del Ámbar (San Nicolás de Tolentino) o Punta del Ámbar (Telde) la referencia lógica apunte al producto animal, y cuando el topónimo sea de interior, como Montaña del Ámbar (Telde) o Morro del Ámbar (Artenara) se esté refiriendo al color amarillo de sus respectivos suelos.

\section{JOVERO}

Jovero, pronunciado siempre así en Canarias, con $/ j /$, por aspiración de la $/ b /$ inicial (el DRAE le da entrada con $b$ y remite a la forma overo, $\sin b$ ), es término poco usado pero que recogen los diccionarios con el significado de 'color parecido al melocotón', con especial aplicación a los

\footnotetext{
31 Diccionario.., cit., s. $v$.
} 
animales. El DRAE dice que "especialmente al caballo", mientras que el DUE precisa diciendo que es término aplicado al 'color de animales', cualquiera que sea, lo mismo que el Larousse ${ }^{32}$.

En Canarias nadie había registrado el término (en el TLEC aparece bobero, recogido en el ALEICan en Lanzarote, pero como variante fonética de hogero, y éste con el significado 'lucero, animal con una mancha en la frente') hasta Almeida, en su obra sobre el habla rural de Gran Canaria ${ }^{33}$, aplicado al color de las cabras.

En la toponimia de Gran Canaria el término Jovero da nombre a tres puntos del terreno, los tres del municipio de Agüimes: Jovero, Montaña Jovero y Casas de Jovero. Podría pensarse, sobre todo por el régimen preposicional del tercero, que Jovero funciona aquí como apodo y que, por tanto, es más un antropónimo que un cromotopónimo. Mas aun así, lo más probable es que el apodo estuviera motivado por el color del propietario de esas Casas.

\section{LOS NOMBRES DE 'COLOR VERDE'}

El color 'verde' se manifiesta en la toponimia de Canarias únicamente por el lexema Verde y por los compuestos Monteverde y Verdeseca, ya que el diminutivo Verdejo, que designa a una localidad menor del municipio de Guía, más parece un nombre impuesto al lugar a partir del antropónimo homónimo.

VERDE

El adjetivo Verde tiene al menos tres referencias diferenciables en la toponimia de Gran Canaria:

a) el de 'color de la vegetación', que es el que manifiestan topónimos como Andén Verde (Agaete), Tierras Verdes (San Nicolás de Tolentino), La Mancha lerde (Tejeda) (en este caso duplicada la referencia al color verde en el sustantivo y en el adjetivo) o Acusa Verde (Artenara);

b) el de 'color verde', aplicado a elementos elaborados por el hombre, como Cruz Verde (Artenara); y

c) el de 'no color', como en Cabo Verde, pues en este caso el topónimo grancanario no es otra cosa que la referencia histórica a las Islas atlánticas portuguesas con las que Canarias ha tenido muchos lazos.

32 Este término no lo recoge Espejo Muriel en su citada obra.

3. El habla mural en Gran Canaria, cit., 185. 
Relacionado con el sentido a) 'color de la vegetación', aunque clasificados en otros grupos son los términos Oscuro (en el grupo 'color negro') y Mancho (en el grupo 'color de contraste').

\section{MONTEVERDE}

En Canarias se ha lexicalizado el compuesto monte + verde para hacer referencia al tipo de bosque más característico de la flora canaria, el de laurisilva, hasta convertirse en apelativo de uso muy común en la lengua popular y más aun, específicamente, en el lenguaje de la botánica. Pues en Gran Canaria el término está también en la toponimia: Monteverde se llama a un paraje de Teror que conserva todavía restos de la que fue extraordinaria y maravillosa "selva de Doramas", tan citada en la antigüedad por tantos y cantada en versos por Cairasco de Figueroa ${ }^{34}$.

\section{VERDESECA}

Un caso singular de formulación léxica y de antítesis semántica es el topónimo Verdeseca (Agaete), aplicado a un paraje que con la misma rapidez con que se pone verde cuando caen cuatro gotas se seca a los pocos días de cesar las lluvias.

10. LOS NOMBRES DE 'COLOR AZUL'

AZUL

El adjetivo $A z u l$ tiene su escasa presencia en la toponimia canaria para calificar, sobre todo, a los charcos, entendidos éstos como pequeños entrantes de mar, de aguas remansadas, limpias y de intenso color azul. Así, en Gran Canaria, Charco Azul (en Agaete y Las Palmas de Gran Canaria) o Charcos Azules (Mogán). Pero también a un Caletón (Las Palmas de Gran Canaria), a un LLanillo (San Nicolás de Tolentino) y hasta a un Caidero (Mogán).

34 B. Calrasco de Figueroa, Antología poética (Gobierno de Canarias, Viceconsejería de Cultura y Deportes, 1989), 160-1. 


\section{LOS NOMBRES DE 'VARIOS COLORES'}

\section{AZULEJOS}

El término Azulejos, que aparece con cierta frecuencia en la toponimia de Canarias, siempre en plural, es sustantivo no derivado de azul, sino del ár. az-zulaîy, que desde el significado de base de 'ladrillo vidriado de varios colores' (DRAE) se aplica a la toponimia con el de 'terreno de varios colores', y que en realidad es el resultado de una alteración hidrotermal brusca en las tobas volcánicas. En Gran Canaria lo encontramos en topónimos como Barranquillo de los Azulejos (San Nicolás de Tolentino), Morro de los Azulejos (San Bartolomé de Tirajana), Lomo de los Azulejos (San Bartolomé de Tirajana) o, simplemente, Los Azulejos (Mogán y San Nicolás de Tolentino).

\section{LOS NOMBRES DE 'COLOR DE CONTRASTE'}

En la toponimia de Gran Canaria existen varios términos que no designan un color concreto sino que, siendo éste indefinido, su valor semántico radica en servir de contraste con el color del suelo o del entorno. Es el caso de Calzado, -a, Bragado, Lisos, Mancho, Cinta y quizás Tiznado (ver éste término en el grupo 'no color'). Pero su archisemema no es el 'no color' (característico del conjunto léxico encabezado por gris), pues el color existe, aunque sea indeterminado y diferente en cada caso. Por eso la estructura semántica de este conjunto es de tipo equipolente, y no gradual como la de los otros conjuntos examinados, caracterizado cada término por un matiz. independiente de color, que puede representarse así:

\begin{tabular}{|c|c|c|c|c|c|}
\multicolumn{1}{c}{ \pm} & \pm & \pm & \pm & \pm & \pm \\
\hline Calzado & Bragado & Lisos & Mancho & Cinta & Tiznado \\
\hline
\end{tabular}

\section{CALZADA}

En el término municipal de Tejeda, cerca del Roque Nublo, en una zona entre Ayacata y Timagada, hay un lugar denominado La Calzada. Este topónimo nada tiene que ver con el apelativo calzada 'vía de comunicación': ni alli hay, ni ha habido, ni ha podido haber nunca un camino acondicionado que pudiera responder al nombre de "calzada", pues ni es lugar de paso ni la orografía lo permite. A lo que se refiere La Calzada 
de Tejeda es a una elevación del terreno cuyo topónimo puede interpretarse como resultado de la elipsis de "La Piedra Calzada > La Calzada 'piedra que en la base tiene un color diferente al resto'.

El DRAE dice que el adjetivo calzado, $d a$, en su acepción $4^{a}$, "aplícase al cuadrúpedo cuyas patas tienen en su parte inferior color distinto del resto de la extremidad. Y en el habla popular de Canarias, con este mismo sentido ampliado, se aplica a las ovejas con las ubres negras, a una res negra con patas blancas $o$ al revés, a las cabras que tienen alguna $o$ algunas de sus patas de un color distinto al resto del cuerpo, referido a los caballos, etc. (ver TLEC). Es decir, que el rasgo semántico caracterizador del lexema resulta ser siempre 'partes bajas de un animal de color diferente al resto del cuerpo'. Pues este sentido es el que se ha deslizado a la toponimia para dejar nombres como el que comentamos.

\section{BRAGADO}

De la misma forma que Calzado, el término Bragado ha pasado del dominio léxico de los animales al de la toponimia para designar un accidente del terreno de distinto color al del contorno. Como ocurre con Risco Bragado (Las Palmas de Gran Canaria).

El DRAE se lo aplica "al buey y a otros animales que tienen la bragadura de diferente color que lo demás del cuerpon, mientras que el TLEC recoge referencias de Bragado aplicados al buey, al gallo de pelea ade plumaje colorado o melado con manchas redondas blancas", a la cabra "que tiene la parte central de la barriga y del lomo blancos, y el resto del cuerpo de cualquier otro color", a la vaca, etc.

\section{LISOS}

Los Lisos se llama a un risco prolongado y vertical que existe a la salida de Las Palmas en dirección sur, a la altura de la Playa de la Laja. Las características del accidente son las que motivaron su nombre: la superficie plana de la piedra y las franjas horizontales de color que se suceden nítidamente a media altura a lo largo de todo el risco.

\section{MANCHO}

En el municipio de Tejeda hay un topónimo denominado Cruz de lo Mancho cuya referencia es clara en el genérico Cruz (una cruz puesta allí en conmemoración de un suceso local), aunque no lo sea tanto en el específico. En teoría, Mancho puede interpretarse como apócope de Man- 
chado, con el sentido de 'color oscuro que contrasta con el contorno'; pero también como deformación léxica (o simplificación) de mancha o manchón, con el sentido de 'terreno poblado de vegetación'. En este caso, el conocimiento del terreno nos pone en la evidencia de la primera interpretación: lo que allí hay es una gran roca en forma de risco que tiene una franja vertical bien marcada de color oscuro, que contrasta espectacularmente con el resto de la roca; y así se explica la configuración morfológica del topónimo, con ese artículo neutro lo que se hubiera convertido en del Mancho si procediera de manchón, o en de la Mancha si la procedencia fuera de mancha.

\section{CINTA}

De la misma manera, en la toponimia de Gran Canaria se recurre al nombre de Cinta para denominar accidentes del terreno (un risco, un morro, un bajo, una cañada, etc.) caracterizados por una franja de color diferente al resto (más que de un color determinado) que recorre horizontalmente el accidente. El más llamativo quizás sea la "cinta" de los riscos del Roque Nublo, en la vertiente de Timagada; pero topónimos que la contengan los hay también en Mogán (Morro de la Cinta Blanca), en Las Palmas (Bajos de la Cinta), en San Bartolomé de Tirajana (Cañada de la Cinta y Morro de la Cinta), en San Nicolás de Tolentino (Cañada de la Cinta) y en Agüimes (Risco de la Cinta).

\section{LOS NOMBRES DEL 'NO COLOR'}

Desde el punto de vista semántico, tan definidor es el rasgo positivo como el rasgo negativo de una oposición; y sabido es que la semántica estructural basa su método en una de las reglas de oro de la lingüística: "sólo se conoce por oposición". Pues tan pertinente es el rasgo 'color' como el rasgo 'no color', capaces ambos de generar sus respectivos paradigmas léxicos.

El color gris, que es el 'no color' por excelencia, el color que es difícil de precisar por lo poco destacado que resulta, es el más propio y común del terreno, pero justamente por ello el menos nombrado en la toponimia, por lo nulo que resulta como identificador de un lugar. Mas no por ello falta absolutamente. El archilexema del conjunto en el español general es gris, definido en el DRAE como "color que resulta de la mezcla de blanco y negro o azul", y que se caracteriza en el habla por los semas 'poco destacado', 'triste' y 'sin color', puestos de relieve en expresiones tan 
coloquiales como "un hombre gris", "un cielo gris", "una película en blanco y negro", frente a "una película en color", etc.

En la toponimia de Gran Canaria falta el archilexema, pero sí aparecen Ceniciento, Verdugado y Pardilla, estructurados semánticamente en tres posiciones: una intermedia, indiferente al matiz de color o grado medio, y dos extremas, caracterizada una por el rasgo '+ blanco' y la otra por el rasgo '+ negro'. Gráficamente:

\begin{tabular}{|l|c|c|}
+ & \\
\hline Ceniciento & Verdugado & Pardilla \\
\hline
\end{tabular}

\section{CENICIENTO}

El primero de ellos, Ceniciento, etimológicamente del color de la ceniza', lo hallamos como adjetivo calificador de un Roque (Las Palmas de Gran Canaria) y de un Morro (Agüimes).

\section{VERDUGADO}

Verduga tiene en el lenguaje popular y rural de Gran Canaria el valor de 'color grisáceo', aplicado sobre todo a la vaca de pelo basto ${ }^{35}$. "Vaca verduga" es expresión corriente en los ámbitos rurales y ganaderos para referirse a la vaca de color gris. Y de ese ámbito referencial ha pasado a la toponimia para designar un terreno de ese color, El Verdugado (municipio de Guía). Un valor este bien diferente del que le asigna el DRAE, a saber: "vestidura que las mujeres usaban debajo de las basquiñas, para ahuecarlas" y que Covarrubias hace derivar de verdugo (y éste de verde), "por ser redondos como los verdugos del árbol y por ventura de color verden ${ }^{36}$.

\section{PARDILLA}

Hay un lugar en el sureste de Gran Canaria (en el término municipal de Telde) llamado La Pardilla (ahora convertido en populoso barrio) que muy posiblemente recibió ese nombre por el color pardo de sus tierras, tierras de labrantío que siempre fueron. Canarias.

35 Cit. por el TLEC, procedente de un estudio de Pérez Vidal sobre la ganadería en

36 S. Covarrubias: Tesoro de la lengua castellana o española (Madrid: Gredos, 1977), s. v. verdugo. 
Hay otra acepción de este término en el español general, la de 'cierta ave', pero que es desconocida en Canarias, y en todo caso, de tomar esa referencia, lo más lógico es que el topónimo se hubiera fijado en plural, en un indocumentado "Las Pardillas, como suele hacer la toponimia cuando se fija en determinadas clases de pájaros. Y hay una tercera acepción del término en el español de Canarias, referida a 'hierbas de hojas de color crema, flores amarillas y semillas en grana', pero suya especie vegetal sólo se ha recogido en Fuerteventura, siendo propia de terrenos rocosos ${ }^{35}$, lo que no es el caso de La Pardilla de Gran Canaria.

\section{CONCLUSIONES}

En efecto, los nombres de color de la toponimia no forman un conjunto caótico y caprichoso sin organización de ninguna clase; por el contrario, se estructuran en pequeños conjuntos léxicos funcionales gobernados por oposiciones semánticas.

La riqueza léxica de una cromotoponimia cualquiera depende, en primer lugar, como hemos visto, de una realidad geográfica objetiva: el color de los suelos y el de los elementos que en la naturaleza sirven como referencia para nombrar los puntos del terreno (una casa, una cruz, la vegetación predominante, etc.); pero, en segundo lugar, la conformación de una cromotoponimia local depende también de la lengua funcional de esa comarca. Por eso no valen aquí las clasificaciones universales: cada cromotoponimia local constituye un conjunto léxico particular, organizado semánticamente también de manera particular.

El color es un continuum que resulta aprehensible a partir de la lengua, fragmentado en tantas unidades conceptuales y semánticas como palabras tenga esa lengua en esa referencia. Desde el punto de vista semántico, cada semema 'blanco' / 'negro' / 'rojo' / 'amarillo' / 'verde', etc. se lexicaliza en tantas unidades léxicas como matices graduales puedan establecerse en la gama de cada color. Así, los 41 términos que aparecen en la cromotoponimia de Gran Canaria se estructuran en 9 subconjuntos semánticos, organizados a su vez en tres niveles de oposiciones, que podemos representar asi:

" Cf. G. Kunkel: Diccionario Botánico Canario (Las Palmas de Gran Canaria: Edirca, 1986), s. $v$. 


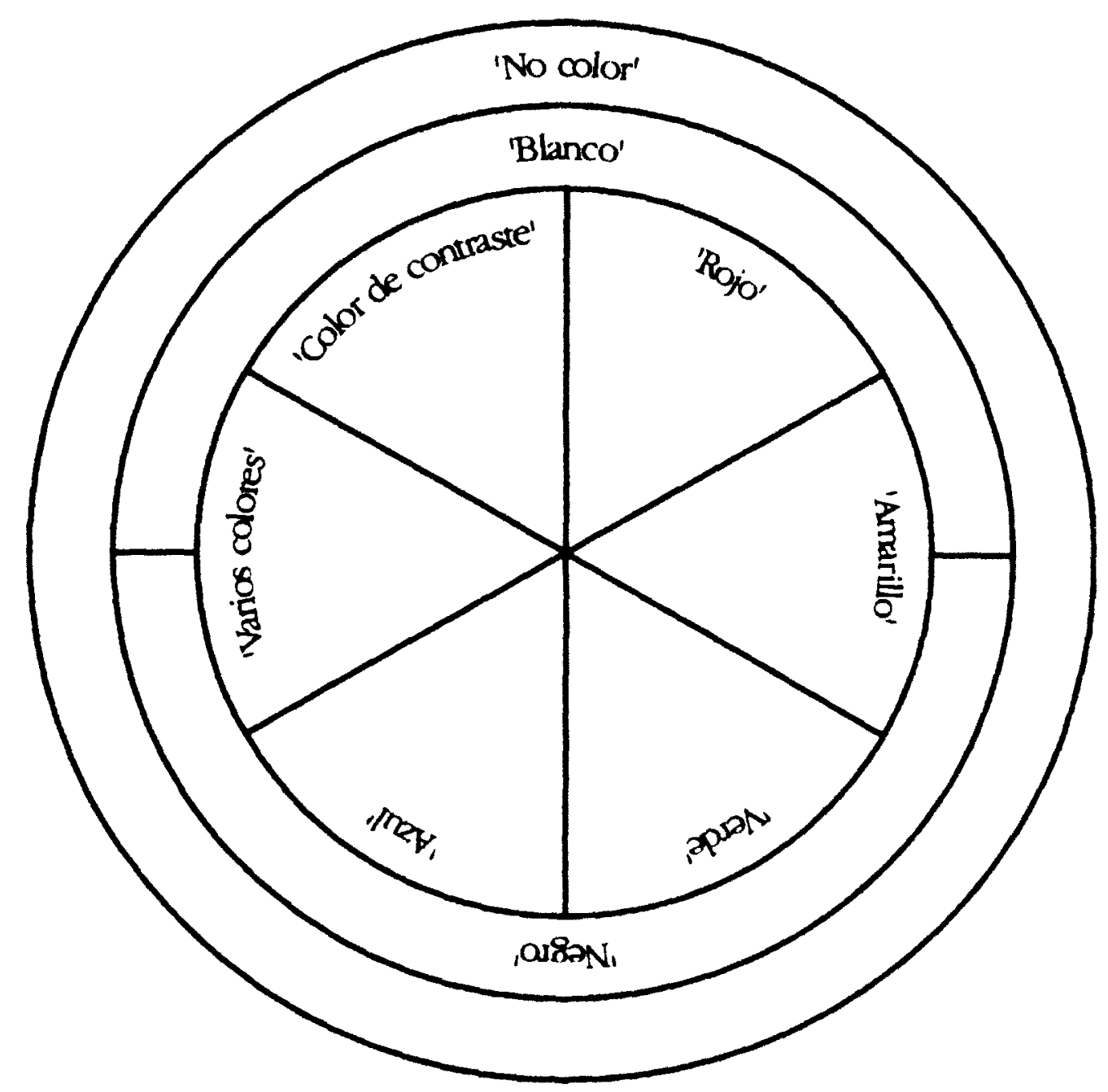

\begin{tabular}{|l|l|l|l|l|l|}
\hline \multicolumn{1}{|c|}{ ROjo } & AMARILO & \multicolumn{1}{|c|}{ VERDE } & AZUL & VARIOS C. & C. CONTruSTE \\
\hline Rojo & Amarillo & Verde & Azul & Azulejos & Cinta \\
Encarnado & Jovero & Monteverde & & & Calzado \\
Colorado & Ámbar & Verdeseca & & & Bragado \\
Las Coloradas & & & & Lisos \\
Coloradillo & & & & & \\
Almagre & & & & & \\
Almasgría & & & & & \\
Almagrés & & & & & \\
Bermejo & & & & & \\
Bermejal & & & & & \\
Zamora & & & & & \\
Sardo & & & & & \\
Rosillo & & & & & \\
Barroso & & & & & \\
\hline
\end{tabular}

\begin{tabular}{|l|l|l|}
\hline \multicolumn{1}{|c|}{ BLANCO } & \multicolumn{1}{|c|}{ NEGRO } & \multicolumn{1}{|c|}{ NO COLOR } \\
\hline Blanco & Negro & Ceniciento \\
Blanquizal & Prieto & Pardilla \\
Plata & Quemado & Verdugado \\
Platero & Moreno & \\
& Oscuro & \\
& Tiznado & \\
\hline
\end{tabular}


En estos gráficos se ponen de manifiesto las siguientes características:

1. El continuum 'color' tiene una configuración circular, no lineal, de donde parece más conveniente representarlo así y no en sentido longitudinal, como lo hace Espejo Muriel.

2. La gama de colores base del arco iris, que es el referente universal del que se parte en la identificación de los colores, puede simplificarse en la toponimia, como ocurre en la cromotoponimia grancanaria, donde se excluyen los colores 'anaranjado' y 'violado'.

3. De la misma forma, los nombres que lexicalizan cada 'color' pueden simplificarse o ampliarse según dos realidades diferenciables pero que actúan complementariamente: la diversidad de colores del terreno y la disponibilidad léxica dialectal.

4. Desde el punto de vista morfológico, el color se lexicaliza en la toponimia grancanaria prioritariamente a través del adjetivo, en un porcentaje del 85 por 100. Por su parte, los adjetivos más comunes, como Blanco, Bermejo o Colorado, se sustantivan con cierta frecuencia en formas como El Blanquizal, El Bermejal o Los Colorados, representando estos sustantivos el 15 por 100 del total de la toponimia de la Isla.

5. De los tres niveles opositivos en que se organiza el conjunto léxico de la cromotoponimia en Gran Canaria, el primero se constituye en un círculo central, dividido en seis subgrupos semánticos, caracterizado cada uno de ellos por un semema 'color' diferenciable en oposiciones de tipo equipolente:

5.1. El 'color rojo', que resulta ser, con mucho, el de una mayor riqueza léxica y, por tanto, el que admite una mayor diferenciación de matices, está representado por los siguientes términos: Rojo, Encarnado, Colorado. Coloradillo, Las Coloradas sust., Almagre, Almagrés, Almagría sust., Almagra sust., Bermejal sust., Bermejo, Zamora, Sardo, Rosillo y Barroso.

5.2. El 'color amarillo', bastante frecuente en la toponimia grancanaria, se lexicaliza a través de Amarillo, Jovero y Ámbar.

5.3. El 'color verde' está representado por tres términos: Verde, Monteverde y Verdeseca, con baja frecuencia los tres. Aquí puede verse la disparidad entre la geografía y la lengua: la isla de Gran Canaria, con ser una isla deforestada al máximo, tiene muchos lugares que no dudaríamos en calificar de verdes, y sin embargo la toponimia sólo se ha fijado en tan pocos. Claro que la referencia a esa cualidad del color verde puede hacerse implícitamente a través de otros topónimos, como Monte, Mancha, Pinar, etc. 
5.4. El 'color azul' sólo tiene un término, su propio lexema $A z u l$, y aplicado preferentemente a los puntos de costa de aguas transparentes y remansadas.

5.5. El semema 'varios colores', desde el punto de vista semántico, es unidad tan simple - y tan discreta - como el 'color azul' o el 'color rojo', en cuanto sirve para identificar a una unidad léxica independiente. En la toponimia de Gran Canaria es el término Azulejos.

5.6. De la misma manera, el semema 'color de contraste', aun sin ser un color definido y uniforme en todos los casos, es tan "color", desde el punto de vista semántico, como cualquier otro, desde el momento en que sirve para identificar una realidad geográfica que tiene una tonalidad diferenciada del contorno, a través del conjunto léxico: Calzado, Bragado. Lisos, Cinta y Mancho.

6. Al círculo central (punto 5) le rodea un segundo círculo de color, dividido éste en dos subgrupos semánticos en oposición binaria y privativa: 'blanco' / 'negro'.

6.1. El 'color blanco' es, con mucho, el color más abundante de la toponimia grancanaria; sin embargo tiene una relativa "pobrezan léxica, representado por cuatro unidades: Blanco, Blanquizal sust., Platero y Plata sust.

6.2. Por el contrario, el 'color negro' se manifiesta muchas menos veces en la toponimia pero a través de un mayor número de términos: Negro, Prieto, Quemado, Moreno, Oscuro y Tiznado.

7. Por último, un tercer círculo exterior, caracterizado por el semema 'no color', que, si bien no contiene oposiciones internas, se diferencia de los otros dos círculos interiores sobre la oposición 'no color' / 'color', está lexicalizado por Ceniciento, Verdugado y Pardilla.

\author{
MAXIMIANO TRAPERO \\ Universidad de Las Palmas de Gran Canaria
}


La toponimia de cualquier lugar puede caracterizarse, entre otras muchas cosas, por los nombres de color que tenga. Tan importante llega a ser esta parcela del léxico en la toponimia general que tiene su propia denominación: la cromotoponimia. Pero los nombres de color resultan de una organización lingüística y no de una clasificación objetiva de la realidad. Esa organización lingüística se basa en la aplicación de los tres tipos de oposiciones semánticas principales: privativas ('color' / 'no color'), equipolentes ('rojo' / 'verde' / 'amarillo', etc.) y graduales ('rojo' / 'bermejo' / 'colorado', etc.). En el presente estudio se analiza la cromotoponimia de la isla de Gran Canaria, especialmente rica y variada, desde el punto de vista de las estructuras semánticas que contrae.

The toponymy of any site can be characterized, among many other way, by the names of the colours found there. This lexical area has become so important in general toponymy that it has its own denomination: chromotoponymy. Rather than being classified according to reality, they are organized linguistically. This linguistic organization is based on the application of the three main types of semantic contrast: privative (color/colourless), equipollent (red/green/yellow, etc.) and gradual (red/bright red/reddish, ruddy, etc.). In this study, the chromotoponymy of the island of Gran Canaria is analised, due to its special wealth and variation, from the point of view of its semantic structures. 